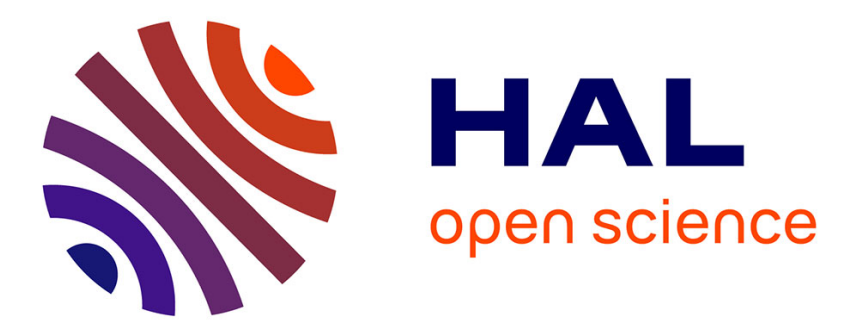

\title{
Polypyrrole nanostructures modified with mono- and bimetallic nanoparticles for photocatalytic $\mathbf{H} 2$ generation
}

Xiaojiao Yuan, Diana Dragoe, Patricia Beaunier, Daniel Bahena Uribe, Laurence Ramos, Maria Guadalupe Méndez-Medrano, Hynd Remita

\section{To cite this version:}

Xiaojiao Yuan, Diana Dragoe, Patricia Beaunier, Daniel Bahena Uribe, Laurence Ramos, et al.. Polypyrrole nanostructures modified with mono- and bimetallic nanoparticles for photocatalytic $\mathrm{H}$ 2 generation. Journal of Materials Chemistry A, 2020, 8 (1), pp.268-277. 10.1039/C9TA11088G . hal-03437340

\section{HAL Id: hal-03437340 https://hal.science/hal-03437340}

Submitted on 23 Nov 2021

HAL is a multi-disciplinary open access archive for the deposit and dissemination of scientific research documents, whether they are published or not. The documents may come from teaching and research institutions in France or abroad, or from public or private research centers.
L'archive ouverte pluridisciplinaire HAL, est destinée au dépôt et à la diffusion de documents scientifiques de niveau recherche, publiés ou non, émanant des établissements d'enseignement et de recherche français ou étrangers, des laboratoires publics ou privés. 


\title{
Polypyrrole Nanostructures Modified with Mono- and Bimetallic Nanoparticles for Photocatalytic $\mathrm{H}_{2}$ Generation
}

Xiaojiao Yuan ${ }^{1}$, Diana Dragoe ${ }^{2}$, Patricia Beaunier ${ }^{3}$, Daniel Bahena Uribe ${ }^{4}$, Laurence Ramos $^{5}$, Maria Guadalupe Méndez-Medrano ${ }^{6}$, Hynd Remita ${ }^{1 *}$

${ }^{1}$ Laboratoire de Chimie Physique, UMR 8000 CNRS, Université Paris-Sud, Université Paris-Saclay, 91405 Orsay, France

${ }^{2}$ Institut de Chimie Moléculaire et des Matériaux d'Orsay, UMR 8182 CNRS, Université Paris-Sud, Université Paris-Saclay, 91405 Orsay, France

${ }^{3}$ Sorbonne Université, CNRS UMR-7197, LRS, 4 Place Jussieu 75005 Paris, France

${ }^{4}$ Laboratorio Avanzado de Nanoscopía Electrónica, Centro de Investigación y de Estudios Avanzados Del I.P.N, Av. Instituto Politécnico Nacional 2508, San Pedro Zacatenco, C.P, 07360, Ciudad de México, Mexico

${ }^{5}$ Laboratoire Charles Coulomb (L2C), Université de Montpellier, UMR 5221 CNRS, 34095 Montpellier, France

${ }^{6}$ Laboratoire de Physique des Interfaces et des Couches Minces, UMR 7647 CNRS, École Polytechnique, 91120 Palaiseau, France

\begin{abstract}
Green hydrogen production by photocatalysis offers a promising way to solve environment and energy issues. Conjugated polymer nanostructures have been demonstrated as a new class of photocatalysts. Here we report that polypyrrole
\end{abstract}


nanostructures are very promising for hydrogen generation. Lamellar mesophases were used as soft templates to synthesize PPy nanostructures (NSs). The PPy-NSs were modified with mono- and bimetallic (Pt, Ni, Pt-Ni) co-catalyst nanoparticles induced by radiolysis. The modified PPy NSs exhibit excellent photocatalytic activity for $\mathrm{H}_{2}$ generation and a synergetic effect is obtained with co-modification with $\mathrm{Pt}$ and $\mathrm{Ni}$. The effect of the nature of the metal precursors and the loading ratio were studied. We show that the loading rate in co-catalysts is crucial for $\mathrm{H}_{2}$ generation and an excess of cocatalyst can drastically decrease the activity. The composite photocatalyst $\mathrm{PPy}-\mathrm{PtNi}$ nanostructures are very active and stable with cycling.

Keywords: Conjugated polymers, Polypyrrole, Nanostructures, Photocatalysis, $\mathrm{H}_{2}$ generation, Solar fuels, Platinum nanoparticles, Nickel nanoparticles.

\section{Introduction}

Hydrogen is a clean, promising and environmental friendly energy source to solve the energy crisis and environmental pollution. The production of hydrogen through a photocatalytic water-splitting process (WSP) has attracted increasing attention. ${ }^{1-3}$ Many studies have focused on inorganic metal oxides (e.g., $\mathrm{TiO}_{2},{ }^{4}, 5 \mathrm{BiVO}_{4},{ }^{6} \mathrm{ZnO}^{7}$ ), (oxy)sulfides (e.g., $\mathrm{CdS},{ }^{8} \mathrm{SnS}_{2}{ }^{9}$ ), and (oxy)nitrides (such as $\mathrm{InN},{ }^{10} \mathrm{GaN}^{11}$ ), which are often based on metal cations possessing $\mathrm{d}^{0}$ and $\mathrm{d}^{10}$ electronic configurations, but generally confined by the relatively limited properties such as large band gap, photocorrosion and self-oxidation. ${ }^{12,13}$ 
Conjugated polymers (CPs) are attracting increasing attention owing to their delocalized conjugated system and outstanding electrochemical property, electrical conductivity, and high carrier mobility. CPs usually have narrow and tunable band gaps, and can absorb UV-Vis and/or near-infrared lights efficiently. We have demonstrated that conjugated polymer nanostructures, such as poly(diphenylbutadyine) (PDPB), ${ }^{14}$ poly(3,4-ethylenedioxythiophene) (P3HT), ${ }^{15}$ poly(3-hexylthiophene) (PEDOT), ${ }^{16}$ and polypyrrole (PPy) ${ }^{17,18}$ exhibit high photocatalytic activities under ultraviolet and visible light irradiation, while their bulk counterpart is not active. We have demonstrated that nanostructuration is a key factor for photocatalytic application of CPs. These conjugated polymer nanostructures were found more active than plasmonic $\mathrm{TiO}_{2}$ under visible light for water treatment and emerge as a new class of photocatalysts. ${ }^{17} \mathrm{CPs}$ are also excellent conductive supports for stabilizing co-catalysts to enhance their properties or extend their functions. ${ }^{19-23}$

Incorporation of metals into semiconductors has demonstrated to be a promising way to promote charge carrier separation. ${ }^{24} \mathrm{Pt}$-based nanoparticles have attracted a lot of interest for applications in catalysis, fuel cells, and photocatalysis. ${ }^{25,}{ }^{26}$ However, because of high cost and scariness of platinum, its replacement by low cost and abundant catalysts (or co-catalysts) is desirable, but remains a great challenge. ${ }^{27}$ Many studies focus on the decrease of the loading with this precious metal by alloying it with another metal of lower cost to increase the photocatalytic activity of the modified photocatalyst for hydrogen evolution. Strategies using $\mathrm{Pd}-\mathrm{Pt},{ }^{28,29} \mathrm{Ni}^{-\mathrm{Pt}^{30,}}{ }^{31}$ or multimetallic $^{27}$ heterojunctions have been investigated. Formation of alloys can reduce the 
metal-metal interatomic distance, induce electronic effects, greatly increase the number of active sites and accelerate the mass transfer between the different active sites. ${ }^{32}$

Here we report for the first time that these modified conjugated polymer polypyrrole nanostructures with mono $(\mathrm{Pt}, \mathrm{Ni})$ and bimetallic $(\mathrm{Pt}-\mathrm{Ni})$ nanoparticles (NPs) are very active for hydrogen generation. Polypyrrole (PPy) nanostructures were synthesized in soft templates formed by lamellar mesophases. Metal nanoparticles $(\mathrm{Pt}$, $\mathrm{Ni}$, and Pt-Ni nanoalloys) of homogeneous size and distribution induced by radiolysis were supported on PPy NPs. Radiolysis is an efficient technique to synthesize metal nanoparticles (NPs) and especially bimetallic NPs of controlled size, distribution and structure in solutions, heterogeneous media or on supports. ${ }^{33,34}$ The obtained composite NSs showed excellent photocatalytic performance for hydrogen generation. The photocatalytic activity of the composite nanomaterials with various metal loading was investigated for hydrogen generation under UV-visible light irradiation.

\section{Experimental section}

2.1. Chemical reagents. Pyrrole ( $\left.\mathrm{Py}, \mathrm{C}_{4} \mathrm{H}_{5} \mathrm{~N}, 98 \%\right)$, as monomer, iron chloride $\left(\mathrm{FeCl}_{3}\right)$ as oxidative agent, sodium dodecyl sulfate (SDS) as surfactant, sodium chloride ( $\mathrm{NaCl})$, cyclohexane $\left(\mathrm{C}_{6} \mathrm{H}_{12}, 99.7 \%\right)$, and n-pentanol $\left(\mathrm{C}_{5} \mathrm{H}_{12} \mathrm{O}, \geq 99 \%\right)$ as co-surfactant were used to synthesize PPy NSs. Platinum(II) acetylacetonate $\left(\mathrm{Pt}\left(\mathrm{C}_{5} \mathrm{H}_{7} \mathrm{O}_{2}\right)_{2}, \geq 99.98 \%\right)$ and nickel(II) acetylacetonate $\left(\mathrm{C}_{10} \mathrm{H}_{14} \mathrm{NiO}_{4}, 95 \%\right)$ were used as platinum and nickel precursors, respectively. All the reagents and methanol $\left(\mathrm{CH}_{3} \mathrm{OH}, 99.9 \%\right)$ were purchased from Sigma-Aldrich, and ethanol $\left(\mathrm{CH}_{3} \mathrm{CH}_{3} \mathrm{OH}, \geq 99 \%\right)$ was purchased from 
VWR International. Deionized water (Milli-Q, 18.6 M 2 ) was used throughout all experiments. All the reagents were pure and used without further purification.

\subsection{Materials preparation.}

(i) Synthesis of PPy NSs: The conjugated polymer nanostructures, polypyrrole (PPy NSs), was prepared using the methodology described in previous publications, but with small modifications. ${ }^{18}$ Briefly, lamellar mesophases were used as a soft template. These mesophases were formed by SDS $(0.8 \mathrm{mg})$ as surfactant, aqueous solution $(2 \mathrm{~mL})$ containing $\mathrm{NaCl}(0.1 \mathrm{M})$, Pyrrole $(100 \mu \mathrm{L})$ in cyclohexane $(6 \mathrm{~mL})$ as oil phase, $\mathrm{n}$ pentanol $(1.2 \mathrm{~mL})$ as a co-surfactant, and $\mathrm{FeCl}_{3}(64.8 \mathrm{mg})$ (for monomer oxidation) in water phase. One mesophase containing Py and one mesophase containing $\mathrm{FeCl}_{3}$ were mixed (as indicated in Figure 1a-b). After 5 minutes, the mesophase obtained after mixing turned from transparent to black indicating the oxidation of Py and its polymerization. The PPy-NSs were extracted by simple washing with ethanol and centrifugation. A black powder was obtained after washing with ethanol and drying in the oven at $60^{\circ} \mathrm{C}$.

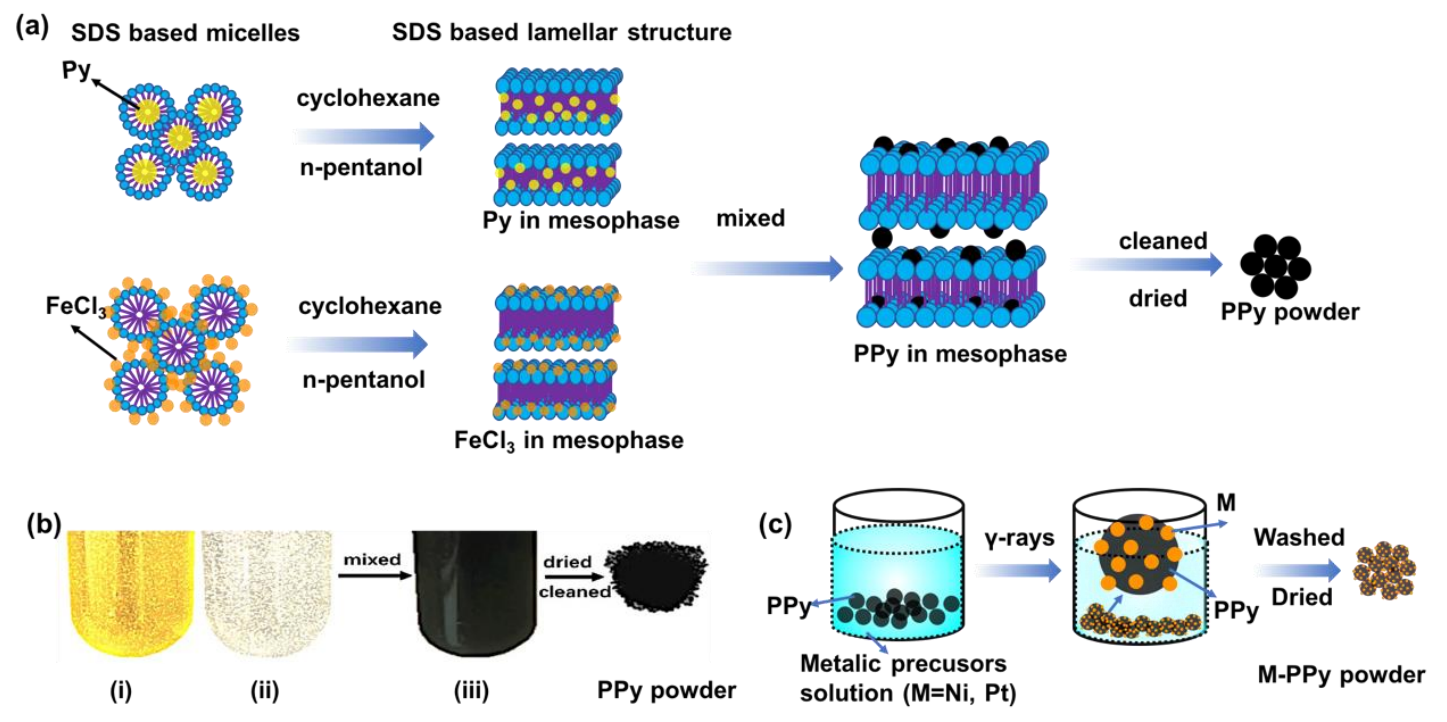


Figure 1. (a) Synthesis process of PPy-NSs using a soft template (a lamellar mesophase); (b) Doped mesophases with (i) $\mathrm{FeCl}_{3}$ and (ii) Py; (iii) PPy-NSs in mesophase; (c) Radiolytic synthesis of metal nanoparticles on PPy NSs (the composite nanomaterials are labeled M-PPy-NSs).

(ii) Pt-PPy-NSs, Ni-PPy-NSs and PtNi-PPy-NSs synthesis: The metal ions were reduced by solvated electrons and alcohol radicals induced by solvent radiolysis. ${ }^{35}$ For each sample, $20 \mathrm{mg}$ PPy-NSs were added into $25 \mathrm{~mL}$ of an aqueous solution containing $0.1 \mathrm{M}$ of ethanol (added as $\mathrm{HO}$ radical scavenger) ${ }^{33}$ and the metallic precursors. $\mathrm{N}_{2}$ was bubbled for 15 minutes to remove oxygen. Then, the samples were exposed to ${ }^{60} \mathrm{Co}$ panoramic $\gamma$-source at a dose rate of $4 \mathrm{kGy} \cdot \mathrm{h}^{-1}$ for 30 minutes (dose $2.0 \mathrm{kGy}$ ). After irradiation, the suspensions were centrifuged and washed with water $(10 \mathrm{~mL})$ for 3 times. Then, the samples were dried at $50{ }^{\circ} \mathrm{C}$ for $2 \mathrm{~h}$ (Figure 1c). Different metal loadings were labeled as $x \% \mathrm{M}-\mathrm{PPy}-\mathrm{NSs}$, where $x \%$ indicates the percentage in mass of the metal with respect to the mass of PPy. The materials were collected by centrifugation. The supernatant was completely transparent indicating that all the metallic species were deposited on the PPy nanostructures.

\subsection{Characterization}

Small Angle X-Ray Scattering (SAXS) was used to characterize the mesophases before and after polymerization. The mesophases doped with only Py, only $\mathrm{FeCl}_{3}$ and containing PPy (obtained after oxidation of Py with $\mathrm{FeCl}_{3}$ ) were put in glass capillaries (diameter $=1.5 \mathrm{~mm}$ ) and high brightness X-Ray tube with low power and an aspheric multilayer optic (GeniX 3D from Xenocs) were employed to deliver an ultralow 
divergent beam $(0.5 \mathrm{mrad})$. A two-dimensional Schneider 2D image plate detector prototype was used to collect the scattered intensity.

Mott-Schottky (MS) plots measurement was carried out by using a typical three electrode setup (Pt wire and $\mathrm{Ag} / \mathrm{AgCl}$ as counter and reference electrodes, respectively). PPy film on FTO as working electrode. The MS spectra were measured in the voltage window of $0.2 \mathrm{~V} \sim 1.0 \mathrm{~V}$ in the dark (increment: $20 \mathrm{mV}$, frequency: $1 \mathrm{kHz}$ ). An aqueous solution of $1 \mathrm{M} \mathrm{NaSO}_{4}$ was used as electrolyte.

UV-Vis adsorption spectra were recorded with a HP 8453 spectrophotometer.

The size, dispersion and morphology of the conducting polymer nanostructures and metal nanoparticles were examined by scanning electron microscopy (SEM, ZEISS Supra 55 V P FEG-SEM) and transmission electron microscopy (TEM, JEOL JEM 2010 UHR operating at $200 \mathrm{kV}$ ). The chemical analyses were obtained by EnergyDispersive X-ray Spectroscopy (EDS) microanalyzer (PGT-IMIX PC) mounted to the microscope. High Angle Annular Dark Field images were obtained using Scanning Transmission Electron Microscopy Cs corrected JEOL-ARM-200F at $200 \mathrm{kV}$.

XPS measurements were performed on a $\mathrm{K}$ Alpha spectrometer from ThermoFisher, equipped with a monochromated X-ray Source $\left(\mathrm{Al} \mathrm{K} \mathrm{K}_{\alpha}, 1486.6 \mathrm{eV}\right)$ with a spot size of $400 \mu \mathrm{m}$. The hemispherical analyzer was operated in CAE (Constant Analyser Energy) mode, with a pass energy of $200 \mathrm{eV}$ and a step of $1 \mathrm{eV}$ for the acquisition of surveys spectra, while for the acquisition of narrow scans, a pass energy of $50 \mathrm{eV}$ and $100 \mathrm{eV}$ and a step of $0.1 \mathrm{eV}$ were used. The charge build-up was neutralized by means of a "dual beam" flood gun. The obtained spectra were treated by 
means of the Avantage software provided by the manufacturer. A Shirley type background subtraction was used and the peak areas were normalized using the Scofield sensitivity factors. The binding energies were calibrated against the $\mathrm{C} 1 \mathrm{~s}$ binding energy set a $284.8 \mathrm{eV}$. The peaks were analyzed using mixed Gaussian-Lorentzian curves (70\% of Gaussian character).

\section{Photocatalytic Production of Hydrogen}

We used methanol as a hole scavenger. Some works have reported that different sacrificial donors without $\mathrm{H}$ (such as $\mathrm{N}_{2} \mathrm{~S}$ or $\mathrm{I}^{-}$) could enhance the yield of hydrogen during photocatalytic process. ${ }^{36}$ However, their photocatalytic activities are not as efficient as methanol as a hole scavenger.

$\mathrm{H}_{2}$ production from methanol-water mixture solution was assessed in a closed quartz reactor with $\mathrm{N}_{2}$ atmosphere under vigorous stirring. For the experiments, $20 \mathrm{mg}$ of the photocatalyst was dispersed in $20 \mathrm{~mL}$ of a degassed aqueous solution with 25 vol \% of methanol, as holes' scavenger. The samples were irradiated by an Oriel 300 W Xenon lamp with an infrared water filter for $5 \mathrm{~h}$ under stirring. Every $1 \mathrm{~h}, 0.2 \mathrm{~mL}$ gas sample was taken by a syringe from the quartz reactor. The amount of $\mathrm{H}_{2}$ was determined by gas chromatography (GC) using Shimadzu GC-14B.

\section{Results and discussions}

\subsection{Characterization}

The mesophases doped with $\mathrm{Py}$, with $\mathrm{FeCl}_{3}$ and the mesophase resulting from the mixing of the two previous ones were characterized by small angle X-ray scattering 
(SAXS) (see Figure 2a). All the three samples are lamellar phases, characterized by two peaks located at scattering vectors $\mathrm{q}_{0}$ and $2 \mathrm{q}_{0}$; The increase of the scattered intensity at small $\mathrm{q}$ is also typical of lamellar phases. The spacing (periodicity of the lamellar phase) $\mathrm{d}=2 \square \square / \mathrm{q}_{0}=6.3 \mathrm{~nm}$ is the same for the three samples. We note that the lamellar phase containing the monomer is more ordered (second order peak sharper) than the other samples.

The electrochemical Mott-Schottky measurement was performed to obtain flat band potential which can be given by the intercepts of the extrapolated lines (Slope) (Figure 2b). The carrier concentration $\left(\mathrm{N}_{\mathrm{A}}\right)$ is determined by the equation ${ }^{37}: N_{A}=$ $\frac{2}{e \varepsilon_{r} \varepsilon_{0} \text { Slope }}, \quad$ e is electron charge, $\varepsilon_{\mathrm{r}}$ is the dilecectric constant ( $\sim 10$ for PPy), $\varepsilon_{0}$ is the free space $\left(8.85 \times 10^{-14} \mathrm{Fcm}^{-1}\right)$. The $\mathrm{N}_{\mathrm{A}}$ of PtNi-PPy $\left(17.7 \times 10^{19} \mathrm{~m}^{-3}\right)$ is five times than PPy $\left(3.5 \times 10^{19} \mathrm{~m}^{-3}\right)$, indicating enhanced electronic conductivity, which will lead to decrease of charge carrier recombination and better electron transfer. ${ }^{38,} 39$

$\mathrm{UV}$-Vis spectrum of PPy exhibits an absorption in the visible region $(400 \mathrm{~nm} \sim 700$ $\mathrm{nm}$ ) and near-IR region (700 $\mathrm{nm} \sim 1000 \mathrm{~nm}$ ) (Figure 2c). The peak at $470 \mathrm{~nm}$ is owing to the $\pi-\pi^{*}$ transitions. The corresponding band gap (Eg) of PPy was determined from the Kubelka-Munk function (Figure 2d): the value of Eg of PPy was found to be 2.2 $\mathrm{eV}$, which is similar to that of previous reports. ${ }^{18}$ 

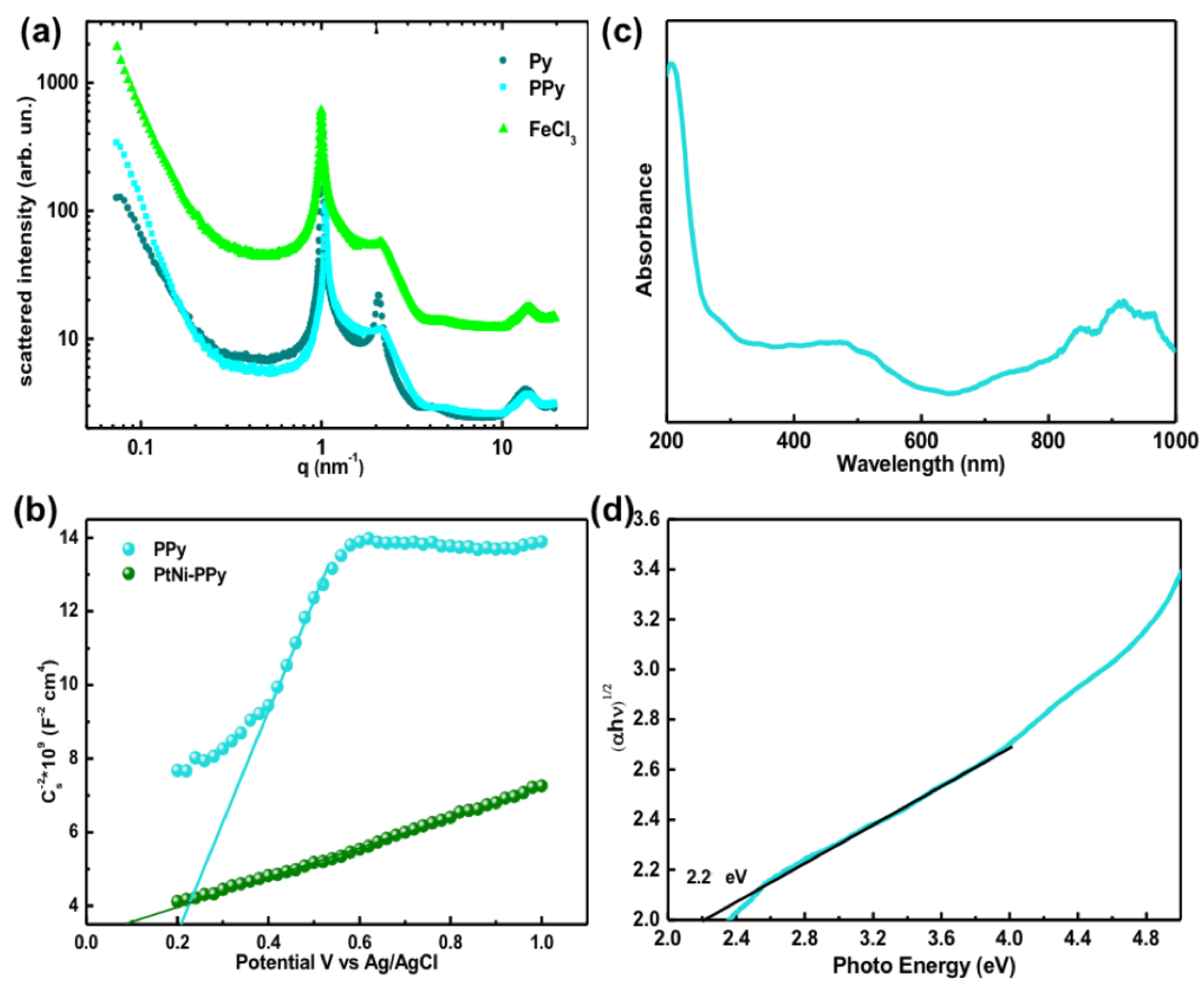

Figure 2. (a) SAXS of the mesophases doped with $\mathrm{Py}, \mathrm{FeCl}_{3}$ and the mesophase resulting from the mixing of the two other mesophases and containing PPy (induced by oxidation of Py by $\mathrm{Fe}^{3+}$ ); (b) Mott-Schottky plot of PPy and PtNi-PPy; (c) UV-Vis spectrum of PPy and (d) corresponding Kubelka-Munk plot.

SEM images show uniform PPy NSs with average size of $40 \mathrm{~nm}$ (Figure S1). TEM was used to characterize the morphology, size, and distribution of the metal nanoparticles (NPs) synthesized by radiolysis and the composite nanomaterials (Figure 3). Aggregates of PPy nanoplates were observed (see Figure 3 a, c, e). For platinum modified polymer nanostructures, well dispersed Pt NPs with a diameter of about 2-3 nm were observed on the surface of PPy NSs (Figure 3a). Figure 3b shows (111) facets of Pt with interplanar spacing of $0.23 \mathrm{~nm}$ indicating the formation of crystalline Pt NPs. For nickel-modified polymer nanostructures, Ni-based NPs of 5-nm diameter and homogeneously dispersed on the surface of PPy-NSs were observed as shown in Figure 
3c-d. Figure 3d presents the interplanar spacing of the Ni-based nanoparticles. The lattice spacings of 0.20 and $0.24 \mathrm{~nm}$ correspond to the (111) plane of $\mathrm{Ni}$ and the (111) plane of $\mathrm{NiO}$, respectively, which proves the presence of $\mathrm{Ni}^{0}$-NiO-based nanoparticles on PPy NSs. In case of co-modification with Pt and Ni, metal NPs of homogeneous size $(2 \mathrm{~nm})$ were observed in Figure 3e showing a smaller crystallite size than monometallic NPs, which support the formation of Pt-Ni nanoalloys. ${ }^{40}$ High-resolution STEM images (Figure 3f) present the lattice spacing of $0.22 \mathrm{~nm}$ and $0.19 \mathrm{~nm}$, which are indexed as the (111) and (200) planes of the fcc PtNi alloys, respectively. EDS analysis of the metal nanoparticles shows that the nanoparticles contain both Pt and Ni (Figure S2) indicating the bimetallic nature of the NPs.

The surface composition and the oxidation states of the metal NPs in the modified PPy NSs were analyzed by X-ray photospectroscopy (XPS). XPS patterns of Pt-PPyNSs, Ni-PPy-NSs and PtNi-PPy-NSs are shown in Figure 4. 

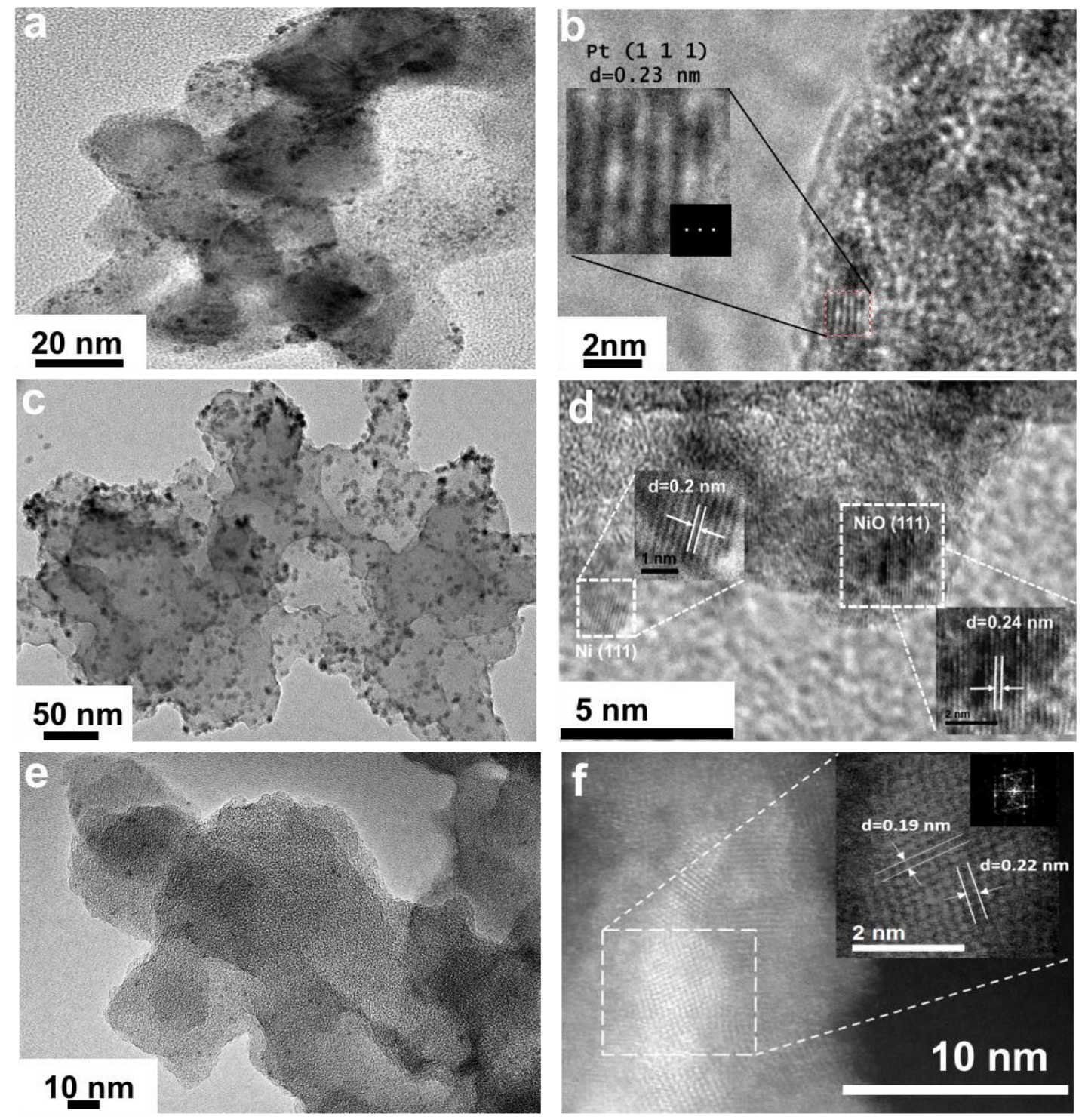

Figure 3. TEM images of $0.2 \% \mathrm{Pt}-\mathrm{PPy}-\mathrm{NSs} \quad(\mathrm{a}-\mathrm{b}), 5 \% \mathrm{Ni}-\mathrm{PPy}-\mathrm{NSs} \quad(\mathrm{c}-\mathrm{d})$, $0.05 \% \mathrm{Pt} 0.05 \% \mathrm{Ni}-\mathrm{PPy}-\mathrm{NSs}$ (e) and HAADF-STEM image of $0.05 \% \mathrm{Pt} 0.05 \% \mathrm{Ni}-\mathrm{PPy}$ (f).

Wide region of spectroscopy of PtNi-PPy-NSs is shown in Figure S3. The signals at $284.1 \mathrm{eV}, 402.5 \mathrm{eV}, 533.2 \mathrm{eV}$ and $201.2 \mathrm{eV}$ correspond to $\mathrm{C} 1 \mathrm{~s}, \mathrm{~N} 1 \mathrm{~s}, \mathrm{O} 1 \mathrm{~s}$ and $\mathrm{Cl}$ 2p, respectively, which are due to PPy. ${ }^{32,}{ }^{41}$ Other signals at $70.5 \mathrm{eV}$ and $53.3 \mathrm{eV}$ correspond to $\mathrm{Pt} 4 \mathrm{f}$ and $\mathrm{Ni} 3 \mathrm{p}$ respectively. The narrow range spectra of $\mathrm{C} 1 \mathrm{~s}$ and $\mathrm{N} 1 \mathrm{~s}$ are depicted in Figure 4a-b, which also proves the presence of PPy. 
The Pt $4 \mathrm{f}$ core-level spectrum shows an intense doublet at $71.7 \mathrm{eV}$ and $75.0 \mathrm{eV}$ corresponding to $\mathrm{Pt} 4 \mathrm{f}_{7 / 2}$ and $\mathrm{Pt} 4 \mathrm{f}_{5 / 2}$ of $\mathrm{Pt}^{0}$ which indicates that $\mathrm{Pt}^{2+}$ was reduced into Pt metal in Pt-PPy-NSs sample (Figure 4c).

The Ni2p core-level spectrum shows the presence of metallic nickel, the component $\mathrm{Ni} 2 \mathrm{p}_{3 / 2}$ at $852.5 \mathrm{eV}$, alongside with its oxide, and hydroxide, which are expected as nickel is very sensitive to oxygen (Figure 4d). ${ }^{42-44}$

Given the low loading levels of both $\mathrm{Ni}$ and Pt, especially in the case of PtNi-PPyNSs (Figure 4e-f), the acquisition conditions were adjusted in order to have the best possible signal/noise ratio in detriment of spectral resolution. Figure $4 \mathbf{e}-\mathbf{f}$ shows that $\mathrm{Pt}$ and Ni nanoparticles are partly oxidized. The Pt $4 \mathrm{f}$ signals represent an intense doublet at $71.4 \mathrm{eV}$ and $74.7 \mathrm{eV}$, corresponding to the core level energies of $\mathrm{Pt} 4 \mathrm{f}_{2 / 7}$ and $\mathrm{Pt} 4 \mathrm{f}_{5 / 2}$ of Pt metal. Other doublets $(71.4 \mathrm{eV}$ and $75.9 \mathrm{eV})$ and $(75.0 \mathrm{eV}$ and $77.9 \mathrm{eV})$ can be ascribed to the +2 and +4 oxidations of $\mathrm{Pt}$, respectively. The peaks at $68.0 \mathrm{eV}$ and 72.4 $\mathrm{eV}$ correspond to the $\mathrm{Ni} 3 \mathrm{p}_{3 / 2}$ and $\mathrm{Ni} 3 \mathrm{p}_{1 / 2}$ correspond to $\mathrm{NiO}$ (Figure 4e) ${ }^{32,45}$ Figure 4f shows the presence of $\mathrm{Ni}$ metal, $\mathrm{NiO}$ and $\mathrm{Ni}(\mathrm{OH})_{2}$. The presence of the oxidized $\mathrm{Pt}$ and Ni species is probably caused by the air during the XPS analysis. It is noteworthy that, in the bimetallic materials (PtNi), the banding energy of Pt is slightly lower by 0.3 $\mathrm{eV}$ compared to the monometallic Pt-PPy, which indicates the strong interaction between the metals and PPy supports. ${ }^{46}$ 
(a)

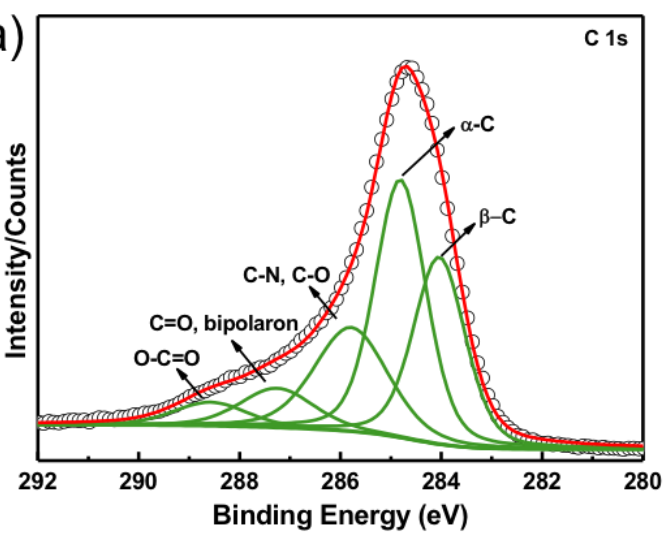

(c)

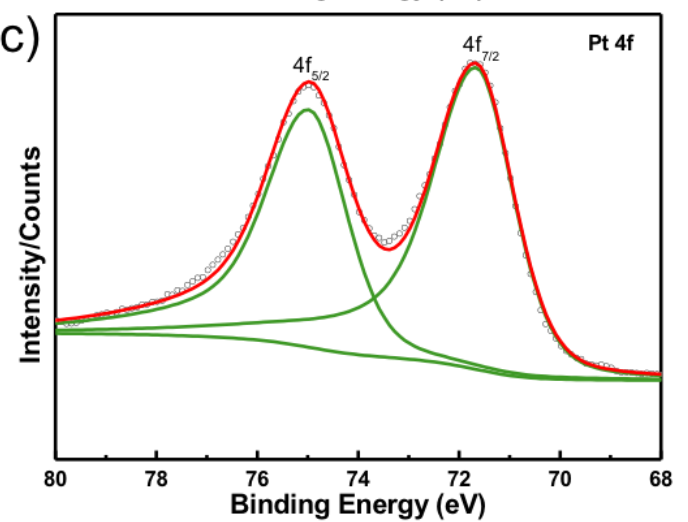

(e)

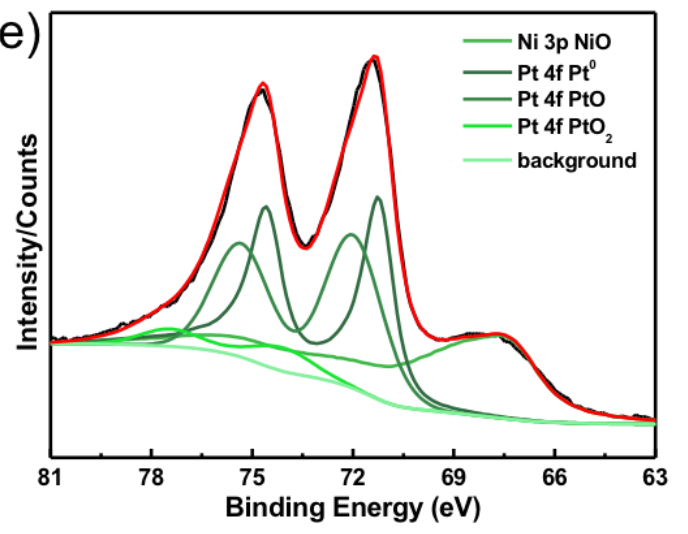

(b)

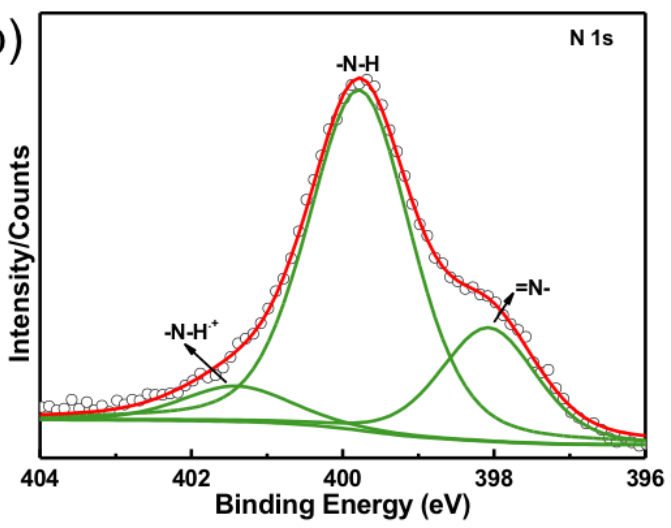

(d)

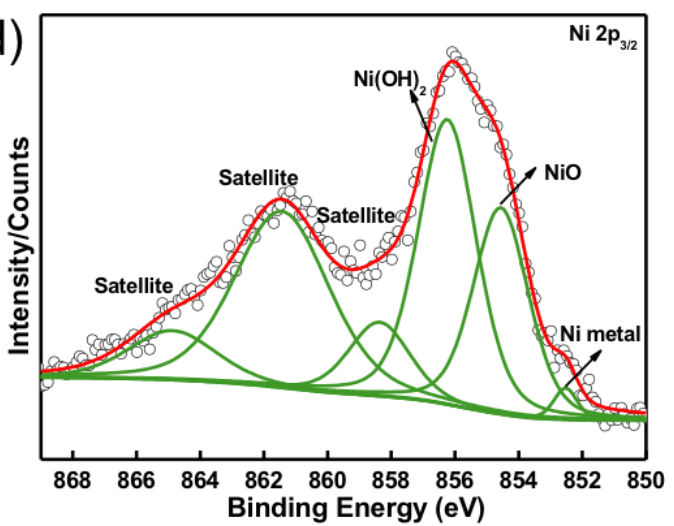

(f)

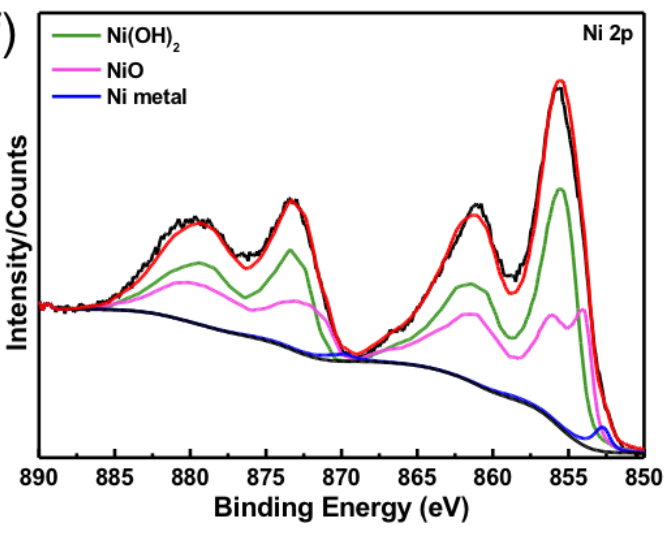

Figure 4. XPS spectra of (a) C1s, (b) N1s in PtNi-PPy-NSs, (c) Pt 4f in Pt-PPy-NSs, (d) narrow scan spectrum of $\mathrm{Ni} 2 \mathrm{p}$ in Ni-PPy-NSs, (e) narrow scan spectrum of nickel states in PtNi-PPy-NSs and (f) narrow scan spectrum of Ni 2p in PtNi-PPy-NSs.

\subsection{Photocatalytic $\mathrm{H}_{2}$ generation}

The addition of co-catalyst (such as $\mathrm{Pt}, \mathrm{Ni}-\mathrm{NiO}, \mathrm{PtNi}$ ) NPs for photocatalytic hydrogen generation can reduce the activation energy of the reaction, provide an active site for proton reduction and $\mathrm{H}-\mathrm{H}$ bond formation and decrease the recombination of 
charge carriers, resulting in an improvement of photocatalytic activity for hydrogen production. ${ }^{43,44}$ In addition, the amount of loading of the co-catalyst is also a crucial factor for hydrogen generation. ${ }^{47}$

\section{Pt-PPy-NSs}

Noble metals with a low Fermi level can trap electrons from the conduction band (CB) of the semiconductor. Among these noble metals, Pt is the best candidate as cocatalyst for hydrogen production due to its largest work function. ${ }^{48}$ The photocatalytic $\mathrm{H}_{2}$ generation efficiency of as-prepared samples was investigated in $25 \mathrm{vol} . \%$ methanol aqueous solution under UV-vis light. As shown in Figures 5a, with time increase, 0.2\%Pt-PPy-NSs show a remarkable enhancement in the photocatalytic activity. Interestingly $0.05 \% \mathrm{Pt}-\mathrm{PPy}-\mathrm{NSs}$ and $0.1 \% \mathrm{Pt}-\mathrm{PPy}-\mathrm{NSs}$ present higher photocatalytic performance compared with nanostructures comprising higher loadings in Pt $(0.3 \%$, $0.5 \%$ and $1 \%$ loading rate). This indicates that higher photocatalytic activity is obtained with a very small amount of co-catalyst. The $\mathrm{H}_{2}$ production rate with $0.2 \% \mathrm{Pt}-\mathrm{PPy}-\mathrm{NSs}$ is $1400 \mu \mathrm{mol} / \mathrm{h} / \mathrm{g}$, and the $\mathrm{H}_{2}$ production rates with $0.05 \% \mathrm{Pt}-\mathrm{PPy}-\mathrm{NSs}$ and $0.1 \% \mathrm{Pt}-\mathrm{PPy}-$ NSs are 312 and $341 \mu \mathrm{mol} / \mathrm{h} / \mathrm{g}$, respectively. For loading larger than $0.2 \%$, the $\mathrm{H}_{2}$ production rate decreases dramatically, showing that an excess metal loading can induce a dramatic decrease of the photocatalytic activity. At high loading, metal nanoparticles can play the role of recombination centers, inducing a decrease in the photocatalytic activity. ${ }^{49}$ Higher metal loading can also induce hindering of the absorption of light by the semiconductor. 
The stability of the photocatalytic activity was investigated with $0.2 \% \mathrm{Pt}-\mathrm{PPy}-\mathrm{NSs}$ under UV-visible light (see Figure 5b). Modified PPy nanostructures with Pt NPs show a very good stability with cycling.
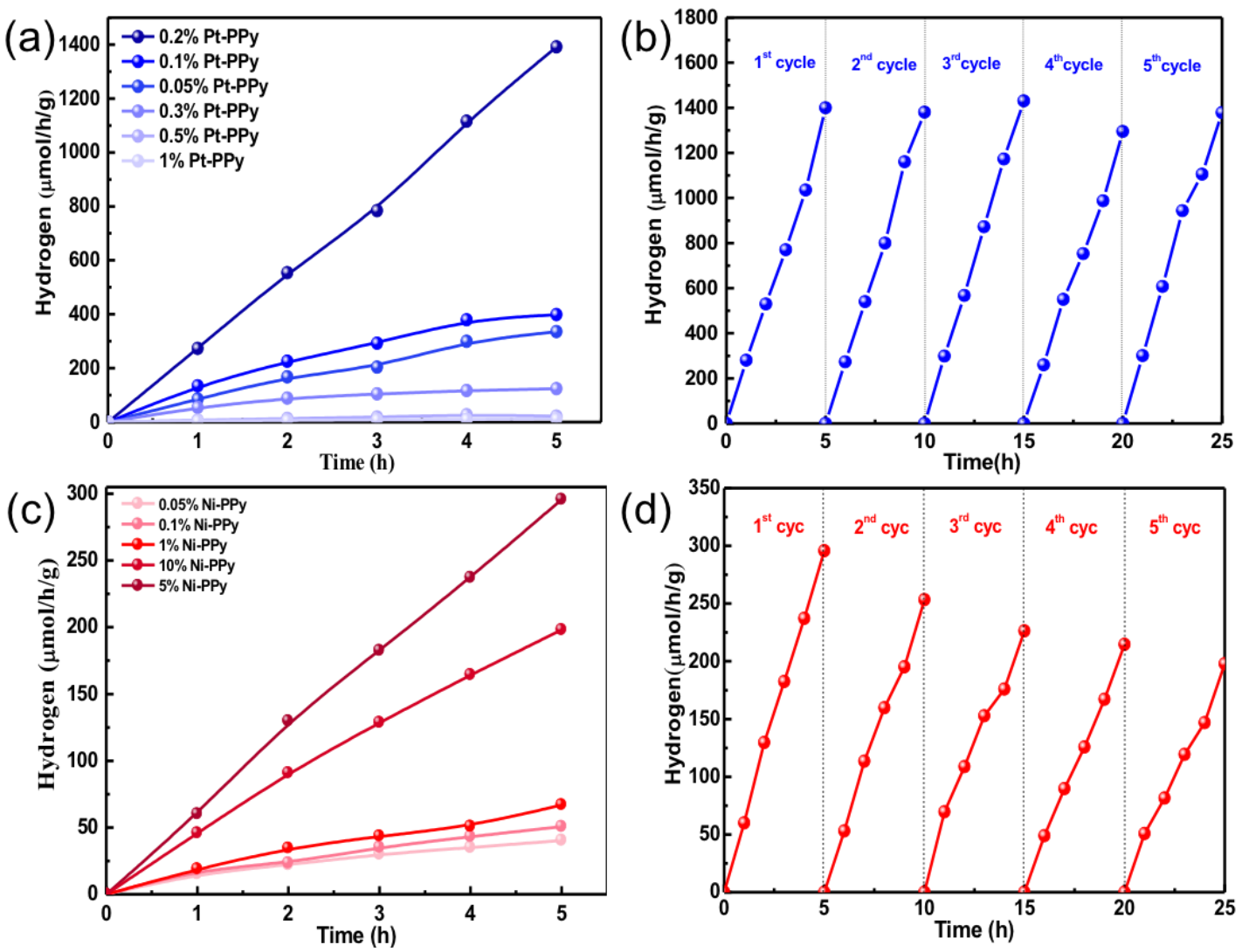

Figure 5. (a) A comparison of the photocatalytic $\mathrm{H}_{2}$ generation rate for different loading rates of PPy-NSs in Pt as indicated in the legend; (b) Hydrogen production with $0.2 \%$ Pt-PPy-NSs after 4 cycles of $5 \mathrm{~h}$; (c) A comparison of the photocatalytic $\mathrm{H}_{2}$ generation rate for different loading rates of $\mathrm{Ni}$ on PPy-NSs as indicated in the legend; (d) Hydrogen production with cycling in the presence of 5\% Ni-PPy-NSs.

\section{Ni-PPy-NSs}

$\mathrm{Ni}$ is also a very promising candidate as co-catalyst for $\mathrm{H}_{2}$ production owing to its low-cost and high photocatalytic properties. ${ }^{43,44,50} \mathrm{Ni}$ nanoparticles do not only provide 
a large surface area and active sites, but also decrease the electron-hole recombination. ${ }^{43,44}$ As shown in Figure 5c, the photocatalytic activity of Ni-PPy-NSs increases with the Ni loading until 5\% loading, then a decrease in the photocatalytic activity is observed. Interestingly, 5\% Ni-PPy-NS exhibits excellent photocatalytic activity for hydrogen production $(289 \mu \mathrm{mol} / \mathrm{h} / \mathrm{g})$, despite the fact that this rate is much lower than that obtained with $0.2 \% \mathrm{Pt}-\mathrm{PPy}-\mathrm{NSs}(1400 \mu \mathrm{mol} / \mathrm{h} / \mathrm{g})$. XPS signals show the concomitant presence of $\mathrm{NiO}$ and $\mathrm{Ni}(\mathrm{OH})_{2}$ (Figure $4 \mathbf{b}$ ). The Fermi level of $\mathrm{NiO}$ is lower than that of $\mathrm{Ni}^{0}$, therefore, the photogenerated electrons in $\mathrm{NiO} / \mathrm{Ni}$ structure migrate from the conduction band of the semiconductor to the Ni layer, and then transfer to the $\mathrm{NiO}$ layer, which leads to efficient charge carrier separation. $\mathrm{Ni}(\mathrm{OH})_{2}$ as co-catalyst can also efficiently transport photogenerated electrons from the conduction band of the semiconductor to $\mathrm{Ni}(\mathrm{OH})_{2} / \mathrm{Ni}$ clusters leading to high photocatalytic activity for hydrogen generation. ${ }^{51}$

It is worth mentioning that the nature of the metal precursors is one of the factors that may strongly affect the size, shape and/or the surface state of the metal nanoparticles, and therefore their activity as co-catalysts. Our results show that PPyNSs modified with metal nanoparticles prepared with platinum (II) acetylacetonate $\left(\mathrm{Pt}\left(\mathrm{C}_{5} \mathrm{H}_{7} \mathrm{O}_{2}\right)_{2}\right)$ and nickel (II) acetylacetonate $\left(\mathrm{Ni}\left(\mathrm{C}_{5} \mathrm{H}_{7} \mathrm{O}_{2}\right)_{2}\right)$, as metallic precursors exhibit higher photocatalytic properties compared with PPy-NSs modified prepared with potassium tetrachloroplatinate (II) $\left(\mathrm{K}_{2} \mathrm{PtCl}_{4}\right)$ and nickel formate $\left(\mathrm{C}_{2} \mathrm{H}_{2} \mathrm{NiO}_{4}\right)$, respectively (Table S1). Cui and co-workers investigated the influence of the metal precursor ligands on the selectivity of alloy particle shape and structures. ${ }^{52}$ Therefore, 
the choice of the metal precursor is very important for the co-catalyst activity for hydrogen production.

The stability of Ni-PPy-NSs with cycling was investigated. As shown in Figure 5d, after 5 cycles, the amount of $\mathrm{H}_{2}$ has dropped by $33 \%$. The small decrease of the photoactivity can be due to the leaching of $\mathrm{Ni}$ nanoparticles during the photocatalytic cycles. Indeed, $\mathrm{Ni}$ is a very efficient catalyst for many reactions, but it is known to leach in water. ${ }^{53}$

\section{PtNi-PPy-NSs}

A strategy to avoid $\mathrm{Ni}$ leaching with cycling, is to alloy $\mathrm{Ni}$ with another noble metal such as Au or Pt. Ni from a Pt-Ni alloy does not dissolve in an electrolyte owing to the $\mathrm{Ni}(\mathrm{OH})_{2}$ passivated surface and the enhanced stability of $\mathrm{Ni}$ in the Pt lattice. ${ }^{45,54}$ To investigate the photocatalytic hydrogen production and stability of the bimetallic (PtNi) doping of PPy-NSs, the experiments were conducted with the same total metal loading rate $(0.1 \%)$ under the same conditions (see in Figure 6a-c). Interestingly, we found that a 50/50 mixture of $\mathrm{Ni}$ and $\mathrm{Pt}$ shows an enhanced photocatalytic activity $(664 \mu \mathrm{mol} / \mathrm{h} / \mathrm{g}$ ) compared with a pure Pt loading $(341 \mu \mathrm{mol} / \mathrm{h} / \mathrm{g})$ and a pure Ni loading $(52 \mu \mathrm{mol} / \mathrm{h} / \mathrm{g})$

(Figure 6a and Figure S4). Some related works for photocatalytic $\mathrm{H}_{2}$ generation with different photocatalysts have been listed in Table $\mathbf{S 2}$ for comparison. The enhanced photocatalytic activity of PtNi-PPy-NSs may be owing to the increased photoefficiency by Schottky barrier leading to longer lifetime of charge carriers and strong UV-vis absorption due to the plasmon resonance of $\mathrm{Pt}$ in the UV range ${ }^{55}$ Synergetic effects are 
expected (such as electronic and geometry effects) inducing enhancement of photocatalytic activity. Such synergetic effect for hydrogen production with bimetallic nanoparticles was also recently observed for $\mathrm{Ni}-\mathrm{Au} / \mathrm{TiO}_{2}$ and $\mathrm{Ni}-\mathrm{Pd} / \mathrm{TiO}_{2}$ : The association of $\mathrm{Ni}$ with another metal (such as $\mathrm{Pd}$ or $\mathrm{Au}$ ) induces an increase of the photocatalytic activity of semiconductors for hydrogen production..$^{43,44,56}$ In case of $\mathrm{Ni}-\mathrm{Pd} / \mathrm{TiO}_{2}$, the study of light absorption, charge-carrier dynamics, and photocatalytic activity revealed that the main role of the metal NPs is to act as catalytic sites for recombination of atomic hydrogen. Platinum is very efficient in electron scavenging and proton reduction, while $\mathrm{Ni}$ is a very good co-catalyst for $\mathrm{H}-\mathrm{H}$ bond formation. ${ }^{31,43 \text {, }}$ 44,47

Figure 6b and Figure S5 show the effect of the total metal loading on photocatalytic hydrogen production for sample with a fixed Pt: Ni ration of 1:1 and the catalytic activity strongly depends on the Ni/Pt ratio (Figure S6). The $0.1 \% \mathrm{PtNi}-\mathrm{PPy}-$ NSs exhibits the highest photocatalytic activity yield rate of hydrogen compared with the PPy modified with other loading rates. Figure 6c shows very high stability with cycling, which indicates that PtNi-PPy-NSs are much more stable than Ni-PPy-NSs during the photocatalytic cycle tests. 
(a)

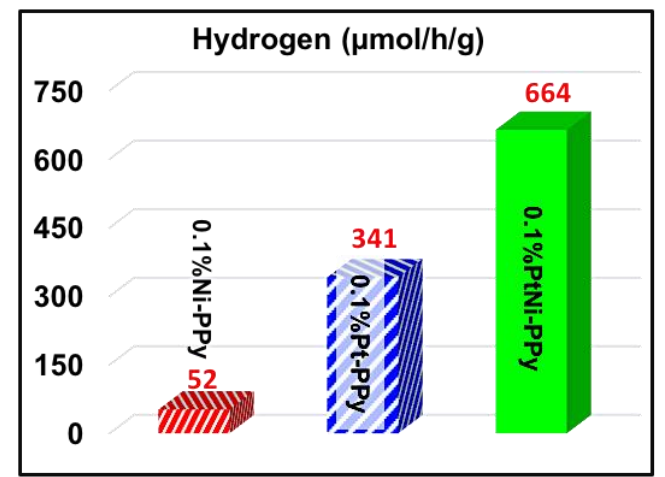

(c)

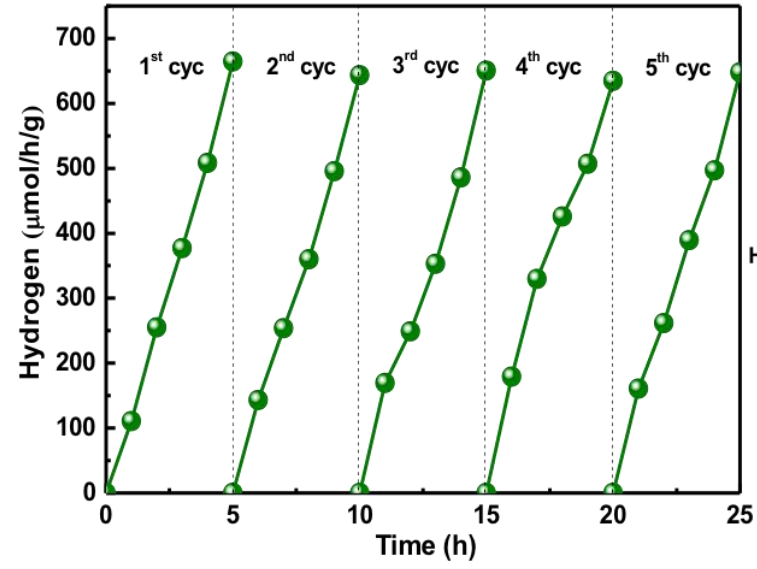

(b)

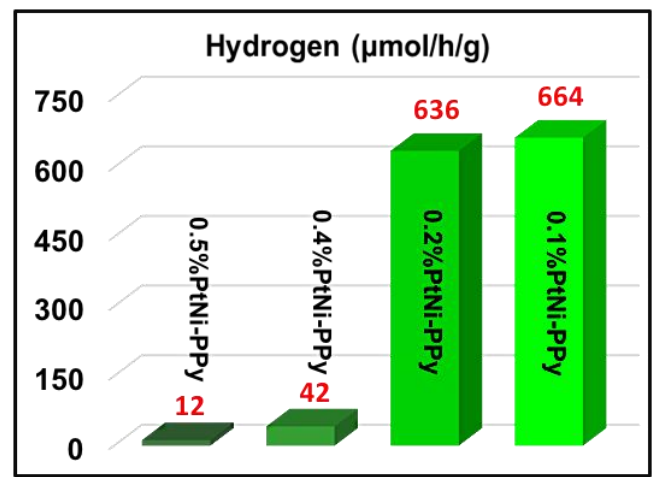

(d)

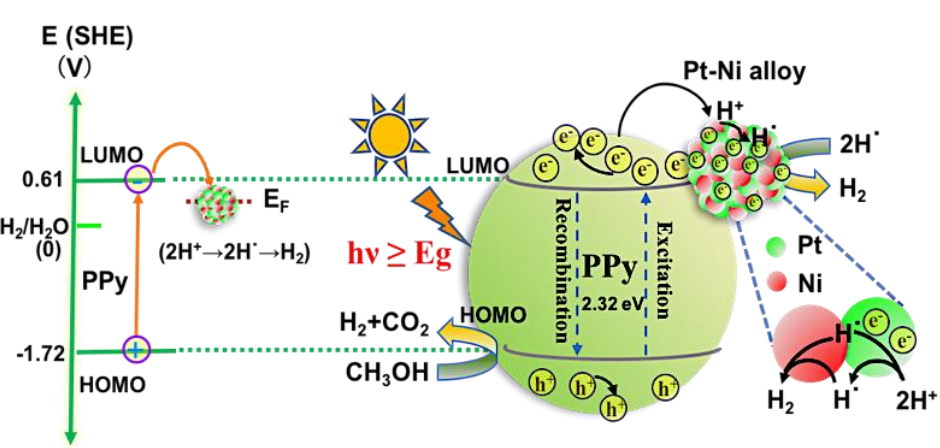

Figure 6 (a) Photocatalytic $\mathrm{H}_{2}$ generation rate with the same loading rate for different samples. (b) The photocatalytic $\mathrm{H}_{2}$ generation rate for different loading rate of $\mathrm{Ni}-\mathrm{Pt}$ on PPy-NSs. (c) Hydrogen production with cycling in the presence of $0.1 \% \mathrm{PtNi}-\mathrm{PPy}-$ NSs. (d) Proposed photocatalytic mechanism for hydrogen generation. Metal NPs act as electron traps, and protons reduction catalysts.

The mechanism of hydrogen formation is similar to that proposed for $\mathrm{Pd}-\mathrm{Ni} / \mathrm{TiO} 2$ and $\mathrm{Au}-\mathrm{Ni} / \mathrm{TiO}_{2}{ }^{43,44}$ The proposed photocatalytic mechanism for hydrogen generation is shown in Figure 6d. The generation of the electron-hole pair takes place in the organic semiconductor PPy NSs. When the energy of the incident light is higher or equal to the band gap of PPy-NSs, the photogenerated electrons can be promoted from the HOMO to the LUMO of PPy nanostructures, leaving holes in the HOMO of PPyNSs (PPy-NSs $\rightarrow \mathrm{h}^{+}+\mathrm{e}^{-}$). Water molecules are reduced by the electrons to produce $\mathrm{H}_{2}$ 
$\left(\mathrm{H}_{2} \mathrm{O}+\mathrm{e}^{-} \rightarrow \mathrm{H}_{2}+\mathrm{OH}^{-}\right)$in the presence of co-catalysts. Methanol was used as a hole scavenger: $\mathrm{CH}_{3} \mathrm{OH}$ reacts with the holes to give $\mathrm{CO}_{2}$ and $\mathrm{H}_{2}$. This hole scavenging results in better charge carrier separation and leads to enhancement of light conversion quantum yield. ${ }^{57}$ Platinum is known to be an efficient sink for electrons. ${ }^{58}$ The presence of Pt-based nanoparticles decreases the charge carrier recombination, and therefore induces the increase of the quantum yield. The excited electrons migrate from PPy-NSs to the metal NPs, and then $\mathrm{H}^{+}$are reduced on the metal surface to promote the proton reduction to generate atomic hydrogen, while these atomic hydrogen recombine to produce the molecular hydrogen (Figure 6d). ${ }^{59}$ The metal nanoparticles (such as $\mathrm{Pt}, \mathrm{Ni}$ and $\mathrm{Pt}-\mathrm{Ni}$ ) not only serve as an electron sinks, but also provide effective proton reduction sites due to its relatively low over-potential. ${ }^{43} \mathrm{Ni}$-based nanoparticles are very active co-catalysts in $\mathrm{H}^{\cdot}$ recombination to form $\mathrm{H}_{2} \cdot{ }^{43},{ }^{44}$ Finally, $\mathrm{H}^{\cdot}$ recombination appears on the surface of the metal NPs producing molecular hydrogen $\mathrm{H}_{2}$, which is facilitated by the presence of $\mathrm{Ni}$. The enhancement of hydrogen generation compared with that of the monometallic samples is owing to a synergetic effect between $\mathrm{Ni}$ and Pt: The presence of $\mathrm{Pt}$ induces better electron scavenging and higher $\mathrm{H}^{*}$ production, while the association with $\mathrm{Ni}$ promotes $\mathrm{H}^{\cdot}$ recombination leading to higher $\mathrm{H}_{2}$ production. Furthermore, the modification with bimetallic Pt-Ni nanoparticles leads to photocatalysts with high stability with cycling.

\section{Conclusion}


Our study shows that conjugated polymer nanostructures modified with metal nanoparticles are promising for green hydrogen production. PPy nanostructures were successfully synthesized in soft templates formed by lamellar mesophases. Monometallic Pt, Ni-NiO and bimetallic Pt-Ni nanoparticles of homogeneous size and dispersion on the surface of PPy NSs were deposited on PPy-NSs by radiolytic reduction. The modified PPy-NSs are very active in hydrogen generation under UVvisible light, and their photocatalytic activity is very sensitive to the metal loading. $0.2 \% \mathrm{Pt}-\mathrm{PPy}-\mathrm{NSs}$ presents the best activity compared with the other percentage loading rates. Modification with nickel-based nanoparticles gives also promising results for green hydrogen production. 5\%Ni-PPy-NSs show enhanced photocatalytic performance due to the formation of the heterojunction between PPy and NiO-Ni nanoparticles. However, the phototocatalytic activity decreases slightly with time, probably because of Ni leaching. The choice of the metal precursors used in the NPs synthesis is important for the activity of the metal co-catalysts: The best activities were obtained using $\mathrm{Ni}$ and $\mathrm{Pt}$ acetylacetonates as precursors for the metal-based nanoparticles. The stability and the photocatalytic activity of Ni-based photocatalysts were much improved by alloying $\mathrm{Ni}$ with Pt. Pt-Ni-PPy exhibit higher activity compared to its monometallic counterparts, and a synergetic effect is obtained. The presence of Pt leads to better electron scavenging and higher $\mathrm{H}^{\cdot}$ formation, while the association with $\mathrm{Ni}$ promotes $\mathrm{H}^{\cdot}$ recombination leading to higher $\mathrm{H}_{2}$ generation. These nanostructures are also very stable with cycling. 
Further studies will focus on development of composite materials based on conjugated polymer nanostructures modified with co-catalysts made of abundant elements for solar fuel production.

\section{Acknowledgements}

X.Y. gratefully acknowledges the financial support from China Scholarship Council (CSC). This work was supported by the IDEX Paris-Saclay and IRS MOMENTOM.

\section{Reference}

1. A. Kudo and Y. Miseki, Chemical Society Reviews, 2009, 38, 253-278.

2. T. Hisatomi, J. Kubota and K. Domen, Chemical Society Reviews, 2014, 43, $7520-7535$.

3. K. Maeda, A. Xiong, T. Yoshinaga, T. Ikeda, N. Sakamoto, T. Hisatomi, M. Takashima, D. Lu, M. Kanehara and T. Setoyama, Angewandte Chemie, 2010, 122, 4190-4193.

4. J. Yu, L. Qi and M. Jaroniec, The Journal of Physical Chemistry C, 2010, 114, 13118-13125.

5. A. Tanaka, S. Sakaguchi, K. Hashimoto and H. Kominami, ACS Catalysis, 2012, 3, 79-85.

6. P. Li, X. Chen, H. He, X. Zhou, Y. Zhou and Z. Zou, Advanced Materials, 2018, 30, 1703119.

7. B. E. Sernelius, K.-F. Berggren, Z.-C. Jin, I. Hamberg and C. G. Granqvist, Physical Review B, 1988, 37, 10244.

8. S. Chen and L.-W. Wang, Chemistry of Materials, 2012, 24, 3659-3666.

9. T. Di, B. Zhu, B. Cheng, J. Yu and J. Xu, Journal of Catalysis, 2017, 352, 532541.

10. Z. Su, H. Li, P. Chen, S. Hu and Y. Yan, Catalysis Science \& Technology, 2017, 7, 5105-5112. 
11. M. G. Kibria, R. Qiao, W. Yang, I. Boukahil, X. Kong, F. A. Chowdhury, M. L. Trudeau, W. Ji, H. Guo and F. Himpsel, Advanced Materials, 2016, 28, 83888397.

12. G. Liao, Y. Gong, L. Zhang, H. Gao, G.-J. Yang and B. Fang, Energy \& Environmental Science, 2019.

13. Y. Inoue, Energy \& Environmental Science, 2009, 2, 364-386.

14. S. Ghosh, N. A. K, L. Ramos, S. Remita, A. Dazzi, A. Deniset-Besseau, P. Beaunier, F. Goubard, P.-H. Aubert \& H. Remita, Nature Materials, 2015, 14, 505-511.

15. D. Floresyona, F. Goubard, P.-H. Aubert, I. Lampre, J. Mathurin, A. Dazzi, S. Ghosh, P. Beaunier, F. Brisset, S. Remita, L. Ramos and R. Hynd, Applied Catalysis B: Environmental, 2017, 209, 23-32.

16. S. Ghosh, N. A. Kouame, S. Remita, L. Ramos, F. Goubard, P.-H. Aubert, A. Dazzi, A. Deniset-Besseau and H. Remita, Scientific Reports, 2015, 5, 18002.

17. S. Ghosh, T. Maiyalagan and R. N. Basu, Nanoscale, 2016, 8, 6921-6947.

18. X. Yuan, D. Floresyona, P.-H. Aubert, T.-T. Bui, S. Remita, S. Ghosh, F. Brisset, F. Goubard and H. Remita, Applied Catalysis B: Environmental, 2019, 242, 284-292.

19. T. K. Das and S. Prusty, Polymer-plastics Technology and Engineering, 2012, 51, 1487-1500.

20. S. Günes, H. Neugebauer and N. S. Sariciftci, Chemical Reviews, 2007, 107, 1324-1338.

21. J. H. Burroughes, D. D. Bradley, A. Brown, R. Marks, K. Mackay, R. H. Friend, P. Burns and A. Holmes, Nature, 1990, 347, 539.

22. C. X. Guo, M. Wang, T. Chen, X. W. Lou and C. M. Li, Advanced Energy Materials, 2011, 1, 736-741.

23. G. Zhang, Z. A. Lan and X. Wang, Angewandte Chemie International Edition, 2016, 55, 15712-15727.

24. N. Bhandary, A. P. Singh, S. Kumar, P. P. Ingole, G. S. Thakur, A. K. Ganguli and S. Basu, ChemSusChem, 2016, 9, 2816-2823.

25. J. B. Schlenoff and H. Xu, Journal of the Electrochemical Society, 1992, 139, 2397-2401. 
26. Y. Holade, A. Lehoux, H. Remita, K. B. Kokoh and T. k. W. Napporn, The Journal of Physical Chemistry C, 2015, 119, 27529-27539.

27. Z. Cai, Z. Lu, Y. Bi, Y. Li, Y. Kuang and X. Sun, Chemical Communications, 2016, 52, 3903-3906.

28. H. Kobayashi, M. Yamauchi, H. Kitagawa, Y. Kubota, K. Kato and M. Takata, Journal of the American Chemical Society, 2010, 132, 5576-5577.

29. Y. Zhao, F. Pan, H. Li, G. Q. Xu and W. Chen, ChemCatChem, 2014, 6, 454458.

30. N. Cao, J. Su, W. Luo and G. Cheng, International Journal of Hydrogen Energy, 2014, 39, 9726-9734.

31. L. Mao, Q. Ba, S. Liu, X. Jia, H. Liu, W. Chen and X. Li, RSC Advances, 2018, 8, 31529-31537.

32. S. Ghosh, S. Bera, S. Bysakh and R. N. Basu, ACS Applied Materials \& Interfaces, 2017, 9, 33775-33790.

33. J. Belloni, M. Mostafavi, H. Remita, J.-L. Marignier and M.-O. Delcourt, New Journal of Chemistry, 1998, 22, 1239-1255.

34. H. Remita and S. Remita, in Recent Trends in Radiation Chemistry, World Scientific, 2010, pp. 347-383.

35. H. Remita, M. G. Méndez Medrano and C. Colbeau-Justin, Visible Light-Active Photocatalysis: Nanostructured Catalyst Design, Mechanisms, and Applications, 2018, 129-164.

36. A. Galińska and J. Walendziewski, Energy \& Fuels, 2005, 19, 1143-1147.

37. S. Tokgöz, Y. Firat, Z. Safi and A. Peksoz, Journal of The Electrochemical Society, 2019, 166, G54-G60.

38. S. Wang, P. Chen, J. H. Yun, Y. Hu and L. Wang, Angewandte Chemie International Edition, 2017, 56, 8500-8504.

39. J. Li, X. Gao, Z. Li, J. H. Wang, L. Zhu, C. Yin, Y. Wang, X. B. Li, Z. Liu and J. Zhang, Advanced Functional Materials, 2019, 29, 1808079.

40. M. Blosi, S. Ortelli, A. Costa, M. Dondi, A. Lolli, S. Andreoli, P. Benito and S. Albonetti, Materials, 2016, 9, 550.

41. M. Šetka, R. Calavia, L. Vojkůvka, E. Llobet, J. Drbohlavová and S. Vallejos, Scientific Reports, 2019, 9, 8465. 
42. Q. Lu, R. Huang, L. Wang, Z. Wu, C. Li, Q. Luo, S. Zuo, J. Li, D. Peng and G. Han, Journal of Magnetism and Magnetic Materials, 2015, 394, 253-259.

43. A. L. Luna, D. Dragoe, K. Wang, P. Beaunier, E. Kowalska, B. Ohtani, D. Bahena Uribe, M. A. Valenzuela, H. Remita and C. Colbeau-Justin, The Journal of Physical Chemistry C, 2017, 121, 14302-14311.

44. A. L. Luna, E. Novoseltceva, E. Louarn, P. Beaunier, E. Kowalska, B. Ohtani, M. A. Valenzuela, H. Remita and C. Colbeau-Justin, Applied Catalysis B: Environmental, 2016, 191, 18-28.

45. K.-W. Park, J.-H. Choi, B.-K. Kwon, S.-A. Lee, Y.-E. Sung, H.-Y. Ha, S.-A. Hong, H. Kim and A. Wieckowski, The Journal of Physical Chemistry B, 2002, 106, 1869-1877.

46. F. Wang, Y. Jiang, D. J. Lawes, G. E. Ball, C. Zhou, Z. Liu and R. Amal, ACS Catalysis, 2015, 5, 3924-3931.

47. B. Mei, K. Han and G. Mul, ACS Catalysis, 2018, 8, 9154-9164.

48. L. Zhang, N. Pan and S. Lin, International Journal of Hydrogen Energy, 2014, 39, 13474-13480.

49. M. Méndez-Medrano, E. Kowalska, A. Lehoux, A. Herissan, B. Ohtani, S. Rau, C. Colbeau-Justin, J. Rodríguez-López and H. Remita, The Journal of Physical Chemistry C, 2016, 120, 25010-25022.

50. L. F. Garay-Rodríguez, S. Murcia-López, T. Andreu, E. Moctezuma, L. M. Torres-Martínez and J. R. Morante, Catalysts, 2019, 9, 285.

51. Y. Xu and R. Xu, Applied Surface Science, 2015, 351, 779-793.

52. C. Cui, L. Gan, H.-H. Li, S.-H. Yu, M. Heggen and P. Strasser, Nano letters, 2012, 12, 5885-5889.

53. E. Y. Kaniukov, A. Shumskaya, M. Kutuzau, V. Bundyukova, D. Yakimchuk, D. Borgekov, M. Ibragimova, I. Korolkov, S. Giniyatova and A. Kozlovskiy, Materials Chemistry and Physics, 2019, 223, 88-97.

54. T. Deivaraj, W. Chen and J. Y. Lee, Journal of Materials Chemistry, 2003, 13, 2555-2560.

55. S. Shuang, R. Lv, Z. Xie and Z. Zhang, Scientific Reports, 2016, 6, 26670.

56. S. Oros-Ruiz, R. Zanella, S. E. Collins, A. Hernández-Gordillo and R. Gómez, Catalysis Communications, 2014, 47, 1-6.

57. P. V. Kamat and S. Jin, ACS Energy Lett. 2018, 3, 622-623. 
58. E. Kowalska, H. Remita, C. Colbeau-Justin, J. Hupka and J. Belloni, The Journal of Physical Chemistry C, 2008, 112, 1124-1131.

59. J. B. Joo, R. Dillon, I. Lee, Y. Yin, C. J. Bardeen and F. Zaera, Proceedings of the National Academy of Sciences, 2014, 111, 7942-7947. 